\title{
Development of a dynamic mathematical model for membrane bioelectrochemical reactors with different configurations
}

\author{
$\operatorname{Jian~} \mathrm{Li}^{1} \cdot{\text { Zhen } \mathrm{He}^{1}}^{1}$
}

Received: 11 September 2015 / Accepted: 13 October 2015 / Published online: 26 October 2015

(C) Springer-Verlag Berlin Heidelberg 2015

\begin{abstract}
Membrane bioelectrochemical reactors (MBERs) integrate membrane filtration into bioelectrochemical systems for sustainable wastewater treatment and recovery of bioenergy and other resource. Mathematical models for MBERs will advance the understanding of this technology towards further development. In the present study, a mathematical model was implemented for predicting current generation, membrane fouling, and organic removal within MBERs. The relative root-mean-square error was used to examine the model fit to the experimental data. It was found that a constant to determine how fast the internal resistance responds to the change of the anodophillic microorganism concentration could have a dominant impact on current generation. Hydraulic cross-flow exhibited a minor effect on membrane fouling unless it was reduced below $0.5 \mathrm{~m} \mathrm{~s}^{-1}$. This MBER model encourages further optimization and eventually can be used to guide MBER development.
\end{abstract}

Keywords Bioelectrochemical system · Microbial fuel cell · Membrane separation · Mathematical modeling · Wastewater treatment

Responsible editor: Marcus Schulz

Electronic supplementary material The online version of this article (doi:10.1007/s11356-015-5611-3) contains supplementary material, which is available to authorized users.

Zhen $\mathrm{He}$

zhenhe@vt.edu

1 Department of Civil and Environmental Engineering, Virginia Polytechnic Institute and State University, Blacksburg, VA 24060, USA

\section{Introduction}

Integrating filtration membranes into bioelectrochemical systems such as microbial fuel cells (MFCs) represents a new approach for sustainable wastewater treatment and has attracted great interest (Yuan and He 2015). In MFCs, bioenergy in wastewater is extracted through the interaction between microbes and electrodes in the anodic compartment and the produced electrons are transferred to a cathode electrode through an external circuit (Logan et al. 2006). Comparing with the conventional activated sludge (CAS) process, MFC technology requires less energy input, yields less sludge, and produces useful bio-electricity ( $\mathrm{Li}$ et al. 2014c; Rabaey and Verstraete 2005; Zhang et al. 2013). Combining a membrane separation process with MFCs helps to achieve high-quality effluent, and the combined system is called membrane bioelectrochemical reactors (MBERs) or bioelectrochemical membrane reactors (BEMRs).

MBERs have been demonstrated feasible and advanced in several aspects including configurations, nutrient removal, and energy balance. Early studies applied biofilm grown on stainless steel mesh as a membrane-like filtration process to achieve high removal of both organics and ammonia (Wang et al. 2011, 2012). Commercial hollow-fiber ultrafiltration membranes were installed in the anodic compartment of a tubular MFC, forming an MBER, but membrane fouling reduced water flux and required frequent membrane cleaning (Ge et al. 2013). To alleviate fouling issue, MBERs were modified, such as a fluidized-bed MBER with granular activated carbon (GAC) in the anodic chamber, or hollow-fiber membrane being installed in the cathodic chamber with constant aeration ( $\mathrm{Li}$ et al. 2014a, b). Nitrogen removal could be improved by using an anion exchange membrane (AEM) as a separator (Li and He 2015). Membrane bioreactors (MBRs) can be linked to MFCs for achieving treatment of wastewater 
or reuse of media for fermentation ( $\mathrm{Li}$ et al. 2015). Two-stage microbial fuel cell-anaerobic fluidized-bed membrane bioreactor generated a high-quality effluent with the MBR as external post-treatment of the MFC (Ren et al. 2014).

Given its intrinsic physical, biological, and electrochemical factors, developing a mathematical model will be helpful for further understanding of MBER systems. An MBER model consists of two parts, MFCs and MBR, linked by some key factors such as organic loading rates (OLR), aeration intensity, and reactor configuration. The available MFC/MEC models are based on Nernst-Monod type of equations to calculate substrate consumption and bacteria growth in the anodic compartment, but the mass transfer equations vary depending on the spatial distribution of substrates and microbial activities (Kato Marcus et al. 2007; Picioreanu et al. 2007; Ping et al. 2014; Pinto et al. 2010). The existing MBR models are derived from activated sludge model (ASM) with a physical membrane filtration process (Ng and Kim 2007). Biomass kinetic models and membrane fouling models are major components to describe the MBR process (Diez et al. 2014; Zuthi et al. 2015). Development of MBER models will need to synergistically integrate MFC models with MBR models. In this study, a dynamic MBER model was developed for the first time. The model was validated and examined with the data from three different MBERs reported previously (Li et al. 2014a, b; Li and He 2015): an MBER with ultrafiltration membranes in its cathodic compartment, an MBER with improved nitrogen removal, and an MBER with fluidized GAC.

\section{Methods}

\section{MBER systems}

The data of three MBER systems published previously were used to examine and validate the developed model, and the schematics of the three MBER systems are shown in Fig. 1. The first MBER, MBER-1, was a cubic reactor containing cation exchange membrane (CEM) as a separator and hollow-fiber membranes installed in its cathodic compartment; the synthetic organic solution was treated in the anode and the effluent flew through the cathode (Li et al. 2014a). The second MBER, MBER-2, was a tubular reactor containing AEM as a separator and operated similarly to the MBER-1; it was designed to enhance nitrogen removal via heterotrophic denitrification in the anode (with nitrate movement across AEM) and bioelectrochemical denitrification in the cathode ( $\mathrm{Li}$ and $\mathrm{He}$ 2015). The third MBER, MBER-3, was a tubular reactor with hollow-fiber membranes installed in its anodic compartment; fluidized GAC was applied for fouling control (Li et al. 2014b).

\section{Model formulation}

Mass balance for substrate, microorganisms, and electron mediators in the anode

The mass balance is established by applying multiplicative Monod kinetics for microbial growth (Pinto et al. 2010). An intracellular redox mediator is assumed to be generated by anodophillic bacteria to aid transfer of the electrons which were produced from substrate degradation. To simplify the process of model formulation, a well-mixing condition is assumed in both chambers, and ordinary differential equation (ODE) is used to calculate the concentration of substrate, anodophillic, and methanogenic microorganism in the anode compartment.

The mass balance for the substrate is shown in Eq. 1:

$$
\begin{aligned}
\frac{d S}{d t}= & D_{\text {anode }} \times\left(S_{\text {in }}-S\right)-k_{s, a, \max } \times \frac{S}{K_{a}+S} \times \frac{M_{o x}}{K_{M}+M_{o x}} \\
& \times C_{a}-k_{s, m, \max } \times \frac{S}{S+K_{m}} \times C_{m}
\end{aligned}
$$

where $S$ is the concentration of substrate $\left(\mathrm{mg}_{-} \mathrm{S} \mathrm{L}^{-1}\right) ; S_{\text {in }}$ is concentration of influent substrate $\left(\mathrm{mg}-\mathrm{S} \mathrm{L}^{-1}\right) ; C_{\mathrm{a}}$ and $C_{\mathrm{m}}$ are the concentrations of anodophillic and methanogenic microorganism $\left(\mathrm{mg}_{-} \mathrm{C} \mathrm{L}^{-1}\right)$, respectively; $k_{\mathrm{s}, \mathrm{a}, \max }$ and $k_{\mathrm{s}, \mathrm{m}, \text { max }}$ are the maximum substrate consumption rates by anodophillic and me-

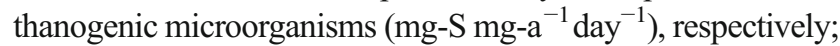
$M_{\mathrm{ox}}$ is the oxidized fraction per anodophillic microorganism (mg-M mg-a ${ }^{-1}$ ); and $K_{\mathrm{a}}, K_{\mathrm{m}}$, and $K_{\mathrm{M}}$ are the half-saturation concentration for the anodophillic microorganisms, methanogenic microorganisms, and the redox mediator $\left(\mathrm{mg}-\mathrm{S} \mathrm{L}^{-1}, \mathrm{mg}-\right.$ $\mathrm{S} \mathrm{L}^{-1}$, and mg-M mg-a ${ }^{-1}$ ), respectively. It is assumed that the growth of anodophillic bacteria is limited by both substrate concentration and the oxidized form of the mediator, whereas the growth of methanogenic microorganism is limited only by the substrate concentration.

$D_{\text {anode }}=\frac{Q_{\text {in }}}{V_{\text {anode }}}$

$D_{\text {anode }}$ is the dilution rate $\left(\right.$ day $\left.^{-1}\right)$, where $Q_{\text {in }}$ is the influent flow rate of the substrate $\left(\mathrm{L} \mathrm{day}^{-1}\right)$, and $V_{\text {anode }}$ is the volume of the anode compartment (L).

The concentration of anodophillic or methanogenic microorganisms is calculated by the differential equations:

$$
\begin{aligned}
\frac{d C_{a}}{d t}= & k_{a} \times C_{a}-k_{d, a} \times C_{a}-D_{\text {anode }} \\
& \times \frac{1+\operatorname{tahn}\left(k_{a, x} \times\left(C_{a}+C_{m}-C_{a, \max }\right)\right)}{2} \times C_{a}
\end{aligned}
$$




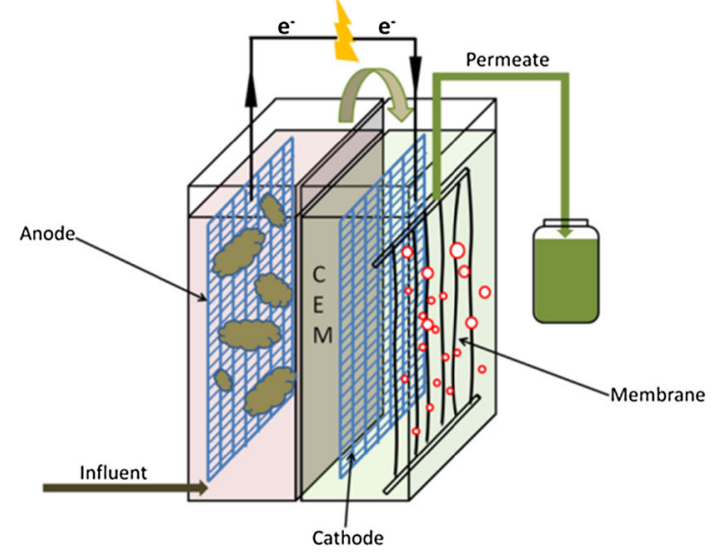

(A)

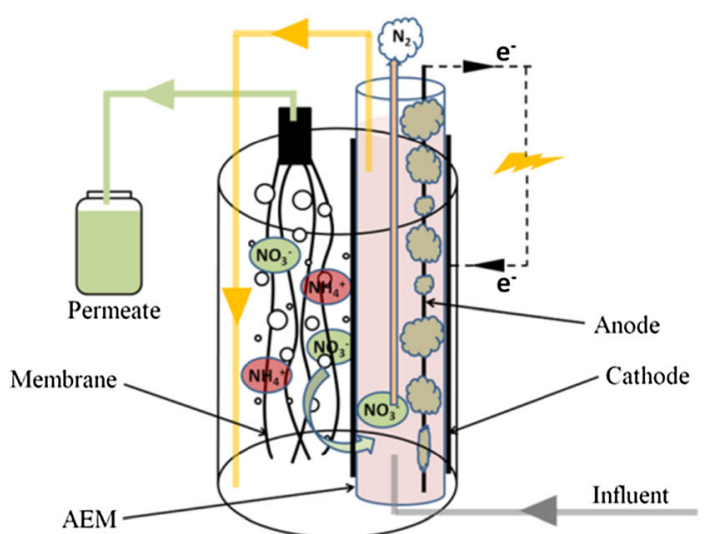

(B)

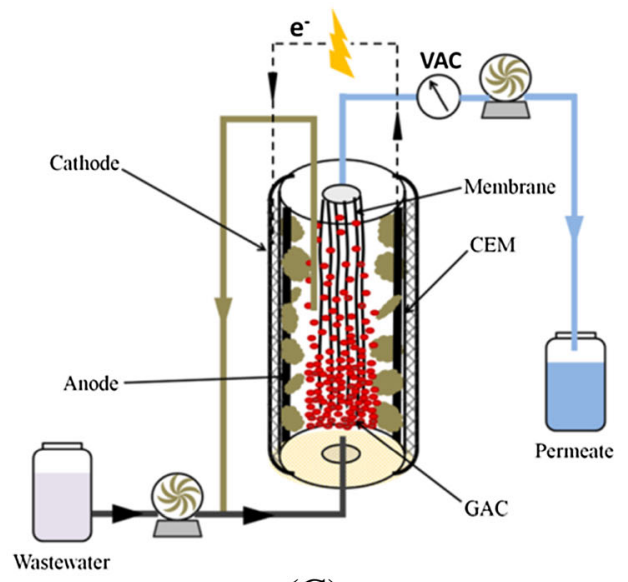

(C)

Fig. 1 Schematics of the previously developed membrane bioelectrochemical reactors (MBERs): a MBER-1, hollow-fiber membranes installed in the cathode; b MBER-2, enhanced nitrogen removal with AEM; and c MBER-3, fluidized GAC in the anode

$$
\begin{aligned}
\frac{d C_{m}}{d t}= & k_{m} \times C_{m}-k_{d, m} \times C_{m}-D_{\text {anode }} \\
& \times \frac{1+\operatorname{tahn}\left(k_{m, x} \times\left(C_{a}+C_{m}-C_{m, \max }\right)\right)}{2} \times C_{m}
\end{aligned}
$$

where $k_{\mathrm{d}, \mathrm{a}}$ and $k_{\mathrm{d}, \mathrm{m}}$ are decay rates of the microorganisms $\left(\right.$ day $\left.^{-1}\right), k_{\mathrm{a}, \mathrm{x}}$ and $k_{\mathrm{m}, \mathrm{x}}$ are the steepness factors for anodophillic microorganisms ( $\mathrm{L} \mathrm{mg-a}^{-1}$ ) and methanogenic microorgan-

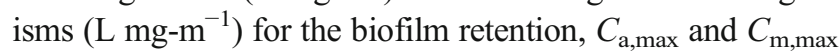
are the maximum attainable concentration for anodophillic microorganisms (mg-a L ${ }^{-1}$ ) and methanogenic microorganisms (mg-m L $\left.{ }^{-1}\right)$, and $k_{\mathrm{a}}$ and $k_{\mathrm{m}}$ are the growth rates of microorganisms $\left(\right.$ day $\left.^{-1}\right)$ calculated by Eqs. 5 and 6 :

$k_{a}=k_{a, \max } \times \frac{S}{K_{a}+S} \times \frac{M_{o x}}{K_{M}+M_{o x}}$

$k_{m}=k_{m, \max } \times \frac{S}{K_{m}+S}$

where $k_{\mathrm{a} \text {,max }}$ and $k_{\mathrm{m} \text {,max }}$ are the maximum microorganism growth rates $\left(\right.$ day $\left.^{-1}\right)$. The intercellular material balance for the oxidized mediator can be described as follows:

$$
\begin{aligned}
\frac{d M_{o x}}{d t} & =-Y_{M} \times k_{s, a}+\frac{\gamma \times I}{V_{\text {anode }} \times C_{a} \times n_{e} \times F} \\
M_{\text {total }} & =M_{\text {ox }}+M_{\text {red }}
\end{aligned}
$$

where $M_{\text {total }}$ is the total mediator fraction per microorganisms ( $\left.\mathrm{mg}-\mathrm{M} \mathrm{mg-a}{ }^{-1}\right), M_{\text {red }}$ is the reduced mediator fraction per microorganisms (mg-M mg-a $\left.{ }^{-1}\right), Y_{\mathrm{m}}$ is the mediator yield (mg-M mg- $\left.\mathrm{S}^{-1}\right), \gamma$ is the mediator molar mass (mg-M mole- $\left.\mathrm{M}^{-1}\right), I$ is the current through the circuit of an $\operatorname{MBER}(\mathrm{A}), F$ is the Faraday constant (A day mole ${ }^{-1}$ ), and $n_{\mathrm{e}}$ is number of electrons transferred per mole of mediator (mole-e mole- $\mathrm{M}^{-1}$ ).

\section{Electrical generation}

The overall cell voltage in an MBER is modeled by the following equation:

$$
I \times R_{\text {ext }}=V_{\text {oc }}-O P_{\text {anode }}-O P_{\text {cathode }}-O P_{\text {conc }}-I \times R_{\text {int }}
$$


where $R_{\text {ext }}$ is the external resistance $(\Omega), V_{\mathrm{oc}}$ is the open circuit voltage $(\mathrm{V}), \mathrm{OP}_{\text {anode }}$ is the anode overpotential $(\mathrm{V}), O P_{\text {cathode }}$ is the cathode overpotential $(\mathrm{V}), \mathrm{OP}_{\text {conc }}$ is the concentration overpotential, and $R_{\text {int }}$ is the internal resistance $(\Omega)$.

Usually, $R_{\text {int }}$ includes mass transfer resistance, ohmic resistance, and activation resistance. In the present study, the internal resistance was calculated as follows:

$R_{\text {int }}=R_{\text {min }}+\left(R_{\max }-R_{\min }\right) \times e^{-k_{r} \times C_{a}}$

where $R_{\min }$ and $R_{\max }$ are the minimum and maximum internal resistance $(\Omega)$ and $k_{\mathrm{r}}$ is the constant that determines how fast the internal resistance respond to the change in microorganism concentration $C_{\mathrm{a}}\left(\mathrm{L} \mathrm{mg-a}{ }^{-1}\right)$.

The open circuit voltage was calculated as:

$V_{o c}=V_{\min }+\left(V_{\max }-V_{\min }\right) \times e^{-1 /\left(k_{r} \times C_{a}\right)}$

where $V_{\min }$ and $V_{\max }$ are the lowest and highest observed $V_{\mathrm{oc}}$ values (V).

The concentration overpotential is assumed to be associated with electron mediators and could be modeled as follows:

$O P_{\text {conc }}=\frac{R \times T}{F} \times \ln \frac{M_{\text {total }}}{M_{\text {red }}}$

It is noteworthy that the anode overpotential and cathode overpotential have been neglected, due to the sufficient buffer solution in both chambers. Hence, the current generation equation is simplified to be as follows:

$I=\frac{V_{o c}-O P_{c o n c}}{R_{e x t}+R_{\text {int }}}$

\section{Membrane fouling}

Membrane fouling issues correlate to a couple of factors, such as wastewater strength, operation condition, hydrodynamic effects, and aeration intensity (Judd 2008). Hence, providing a constant aeration to membrane is a key factor on fouling control.

Membrane simulation of the MBER-1 Due to the similarity of system configuration, submerged membrane bioreactor (sMBR) models are used for membrane performance prediction. Being as a stand-alone technology, sMBR models include aeration, cake formation, filtration, fouling, physical, and bioprocess description (Pimentel et al. 2015). The total membrane fouling is represented by combining cake layer resistance $\left(R_{\text {cake }}\right)$, intrinsic resistance $\left(R_{\mathrm{m}}\right)$, and resistance which is caused by total resistance disturbance $\left(\delta_{\mathrm{R}}\right)$. However, the formation of cake layer is usually responsible for membrane fouling issue (Khan et al. 2009).

$R_{\text {total }}=R_{m}+R_{\text {cake }}+\delta_{R} \approx R_{\text {cake }}$ where the cake layer resistance is calculated by:

$R_{\text {cake }}=\rho \times\left(\frac{m+m_{0}}{A}\right)$

where $\rho$ is the specific cake layer resistance $\left(\mathrm{m} \mathrm{g}^{-1}\right), m_{0}$ is the initial cake mass $(\mathrm{g}), A$ is the area of the membrane surface, and $m$ is the current cake mass $(\mathrm{g})$.

The calculation of the transmembrane pressure is expressed as follow:

$\Delta P=Q_{\text {out }} \times \eta \times R_{\text {total }}$

where $\Delta P$ is the transmembrane pressure $(\mathrm{Pa}), \eta$ is the water apparent viscosity $(\mathrm{Pa} . \mathrm{s})$, and $Q_{\text {out }}$ is effluent rate $\left(\mathrm{m}^{3}\right.$ day $\left.^{-1}\right)$.

The change of the cake layer mass can be expressed:

$\frac{d m}{d t}=Q_{\text {out }} \times X-J_{\text {air }} \times \mu_{\text {air }} \times m$

$\mu_{\text {air }}=\beta \times \frac{m}{K_{\text {air }}+m}$

where $X$ is the concentration of the suspended solids $\left(\mathrm{g} \mathrm{m}^{-3}\right)$, $J_{\text {air }}$ is the air cross-flow $\left(\mathrm{m}^{3} \mathrm{~m}^{-2}\right.$ day $\left.{ }^{-1}\right), \beta$ is linked to the resistance of the cake to detachment $\left(\mathrm{m}^{-1}\right)$, and $K_{\text {air }}$ is the half-saturation coefficient of air flow $(\mathrm{g})$.

The biological activity is described involving one biomass growing on a limited substrate.

$\frac{d S}{d t}=-\frac{1}{Y} \times \mu(S) \times X+\frac{Q_{\text {in }}}{V} \times\left(S_{\text {in }}-S\right)$

$\mu(S)=\mu(S)_{\max } \times \frac{S}{K_{S}+S}$

$\frac{d X}{d t}=\left(\mu(S)-\frac{Q_{W}}{V}\right) \times X+\frac{Q_{\text {in }}}{V} \times X_{\text {in }}-\frac{Q_{\text {out }}}{V} \times X$

$+\frac{J_{\text {air }}}{V} \times \mu \times m$

where $Y$ is yield coefficient of the substrate consumption, $\mu(S)$ is the microbial growth rate $\left(\right.$ day $\left.^{-1}\right), \mu(S)_{\max }$ is the maximum microbial growth rate $\left(\mathrm{day}^{-1}\right), Q_{\text {in }}$ is the inflow rate $\left(\mathrm{m}^{3}\right.$ day $\left.^{-1}\right), V$ is the volume of the cathode chamber $\left(\mathrm{m}^{3}\right), S_{\text {in }}$ is the substrate concentration in the influent flow, $S$ is the substrate concentration $\left(\mathrm{g} \mathrm{m}^{-3}\right), K_{s}$ is the half saturation of substrate $\left(\mathrm{g} \mathrm{m}^{-3}\right), Q_{\mathrm{w}}$ is the waste flux $\left(\mathrm{m}^{3}\right.$ day $\left.{ }^{-1}\right)$, and $X_{\mathrm{in}}$ is the solid concentration in the influent $\left(\mathrm{g} \mathrm{m}^{-3}\right)$.

The parameter $\beta$ represents the ease (or difficulty) of detaching the cake from the membrane using an air cross-flow.

$\frac{d \beta}{d t}=\gamma \times \beta$

Membrane simulation for the fluidized-bed MBER-3 A previous study was used to develop and predict membrane fouling problem in the fluidized MBER system (Liu et al. 2003). The membrane fouling rate under various hydrodynamic conditions has been estimated. 
The filtration resistance is calculated as an indicator for membrane fouling status:

$R=3.6 \times 10^{9} \times \frac{\Delta P}{\eta \times J}$

where $R$ is the filtration resistance $\left(\mathrm{m}^{-1}\right), J$ is filtration flux $\left(\mathrm{L} \mathrm{m}^{-2} \mathrm{~h}^{-1}\right)$, and $\Delta P$ is the transmembrane pressure $(\mathrm{Pa})$. The $\eta$ is approximately expressed by the viscosity of tap water and is calculated as follows:

$\eta=1.6003 \times e^{-0.021 \times T}$

where $T$ is the temperature of water.

It is assumed that the membrane filtration resistance increases with time during the filtration, and the increasing rate of resistance $K$ is obtained as a slope of the straight line to the changing course of the measured resistance.

The increase rate of resistance $K$ is calculated as follows:

$K=f \times U_{L r}^{c} \times J^{d} \times X^{e}$

where $f, c, d$, and $e$ are constants. $X$ is the concentration of suspended solids in mixed liquor $\left(\mathrm{g} \mathrm{L}^{-1}\right), J$ is filtration flux $\left(\mathrm{L} \mathrm{m}^{-2} \mathrm{~h}^{-1}\right) ; U_{L r}$ is the cross-flow velocity on the membrane surface $\left(\mathrm{m} \mathrm{s}^{-1}\right)$.

\section{Nitrogen removal from the MBER-2}

Nitrogen can be removed from an MBER by either ionic migration or diffusion due to the concentration gradient. To quantify the total nitrogen concentration in the membrane permeate:

$$
\begin{aligned}
\frac{d C_{\mathrm{TN}}}{d t}= & \left(C_{T N, i n}-C_{T N}\right) \times D_{\text {cathode }}-\alpha \\
& \times \frac{I}{F \times V_{\text {cathode }}}-\beta \times C_{T N}
\end{aligned}
$$

where $C_{\mathrm{TN}, \text { in }}$ and $C_{\mathrm{TN}}$ are the total nitrogen concentration in the anode effluent and membrane filtrate, respectively, (mole-N L ${ }^{-1}$ ); $D_{\text {cathode }}$ is the dilution rate $\left(\right.$ day $^{-1}$ ) in the cathode compartment that is quantified by the ration of effluent rate $\left(Q_{\text {out }}\right)$ over the volume of the cathode compartment $\left(V_{\text {cathode }}\right) ; \alpha$ is the fraction of produced electrons for total nitrogen removal; $I$ is the current produced (A); $F$ is the Faraday constant; and $\beta$ is the diffusion coefficient for concentration gradient $\left(\right.$ day $\left.^{-1}\right)$.

\section{Parameter estimation}

The information about the estimated parameters can be found in Table S1-3 (Supplemental data). The parameters obtained are further re-estimated from additional experimental data. The genetic algorithm routine in MATLAB is used for parameter estimation to minimize the relative root-mean-square error (RMSE) between the predicted value and the experimental data. The RMSE is calculated as follows:

RMSE $=\frac{\sqrt{\frac{\sum_{i=1}^{N}\left(y_{m}-y_{e}\right)^{2}}{N}}}{\max \left(y_{e}\right)}$

where $N$ is the total number sampling time points in the simulation and $y_{\mathrm{m}}$ and $y_{\mathrm{e}}$ represents model-predicted values and experimental data at $t_{i}$, respectively. The maximum value of experimental data was used to normalize the error in Eq. 27. A smaller RMSE indicates that model has a good fit to experimental data. MATLAB Function ODE23 is applied to solve differentiation equation in this work.

\section{Results and discussions}

\section{Model performance with the MBER-1 data}

The developed model was examined with the data of the MBER-1 that was operated under a hydraulic full-loop mode, and the flow rate of its anode feeding was adjusted at 0.23 , 0.39 , and $0.23 \mathrm{~mL} \mathrm{~min}^{-1}$ on days 20,66 , and 78 , respectively, resulting in an anodic hydraulic retention time (HRT) of 10, 6, and $10 \mathrm{~h}$. The model output of current value shows a general agreement with the experimental measurement, but some underestimation and overestimation can be seen (Fig. 2a). The RMSE indicated that the mean error for the current generation was within $15.2 \%$ of their maximum value during the first 46 days. Such a discrepancy can be observed from the mismatch at the early period: the current simulation was started from day 20 of the MBER operation, and a sharp decrease in the modeled current occurred in a short period of time afterward. The initial anodophillic bacteria concentration was estimated as $345.3 \mathrm{mg} \mathrm{L}^{-1}$, and the lagging time of bacteria growth resulted in a temporary drop of current generation; when the anodophillic bacteria concentration reached a steady state, a stable current generation was achieved as a result. The simulated current generation increased by $0.5 \mathrm{~mA}$ from day 66 , as a response to enhanced organic loading rate, but overestimation can be observed and the RMSE for the current generation was $20.8 \%$. The formulated model has a high sensitivity to the change of organic loading rate, but the experiment did not respond correspondingly, possibly related to the fact that a large amount of organic compounds were consumed by microorganisms rather than anodophillic bacteria. The predicted current generation was below $4 \mathrm{~mA}$ after the feeding flow rate was changed back to $0.23 \mathrm{~mL} \mathrm{~min}^{-1}$ on day 78 with slight overestimation and a RMSE of $18.4 \%$.

The predicted transmembrane pressure (TMP) profile had a very good fit to the experimental data (Fig. 2b), and the 

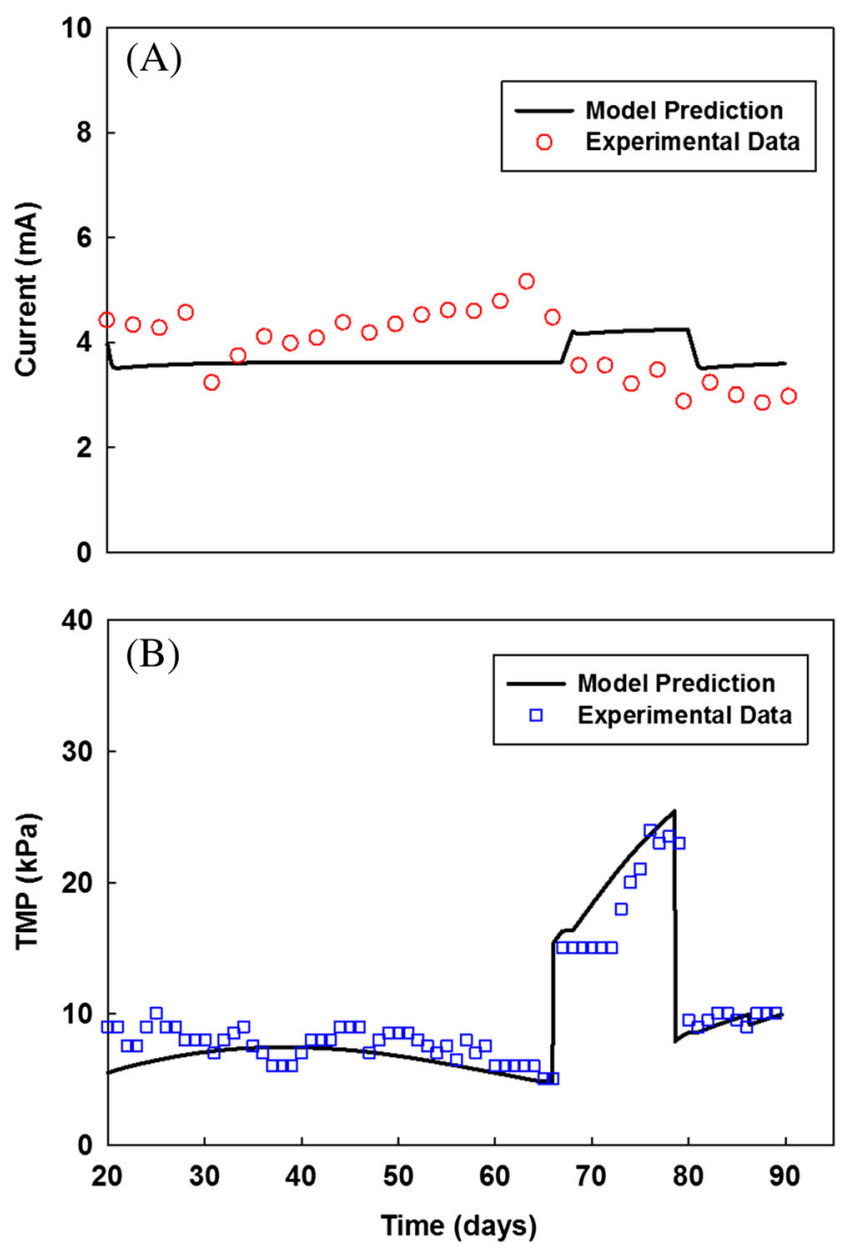

Fig. 2 Experimental data and model simulation of the MBER-1 when the flow rate of the feeding solution was at $0.23,0.39$, and $0.23 \mathrm{~mL} \mathrm{~min}^{-1}$ on days 20,66, and 78, respectively: a current generation and $\mathbf{b}$ TMP change

relative RMSE was $11.3 \%$ when the system was operated at an anodic HRT of $10 \mathrm{~h}$ from days 20 to 66 . The simulated TMP experienced a dynamic process, in which it started from $5 \mathrm{kPa}$ on day 20 , increased to a peak value of $8 \mathrm{kPa}$ on day 40 , and then dropped back to $5 \mathrm{kPa}$. The underestimation of the TMP during the starting period was likely related to the formation of membrane fouling. The arch shape of the TMP change can be explained from Eq. 17, in which the first term represents the attachment of total suspended solids on the membrane surface depending on the effluent rate, and the second term in the equation represents cake detachment proportional to the air cross-flow. Equation 17 indicates that the change of cake layer mass is proportional to the instantaneous cake layer mass, with a factorial of 2 . Hence, the change of cake layer mass follows a parabolic shape and "archy" shape is a portion of the parabola. The change of TMP was less obvious in the experimental measurements due to the method of TMP recording (data were recorded manually three times a day, and the average value was used for analysis). The developed model was further evaluated and validated for TMP by changing the feeding rate to $0.39 \mathrm{~mL} \mathrm{~min}^{-1}$ on day 66 and then to $0.23 \mathrm{~mL} \mathrm{~min}^{-1}$ on day 78 in a stepwise way. The model prediction for TMP generally followed the trend of experimental data, and the simulated TMP increased from 14 to $25 \mathrm{kPa}$ before the anode feeding rate was changed back to $0.23 \mathrm{~mL} \mathrm{~min}^{-1}$. During this period, a linearized change of TMP indicates that the enhanced water flux played a dominant role for cake layer accumulation on the membrane surface, and cake mass detachment from air cross-flow became a marginal effect due to a higher vacuum pressure after water flux adjustment. The change of cake layer mass is proportional to water flux by a factorial of 1 , resulting in a linearized TMP change. The simulated TMP dropped back to $10 \mathrm{kPa}$ along with reduced water flux after the anolyte was fed at $0.23 \mathrm{~mL} \mathrm{m^{-1 }}$ again on day 78 ; it is worth noting that the TMP began to increase from an initial TMP of $10 \mathrm{kPa}$, higher than $5 \mathrm{kPa}$ on day 20 , likely because of irreversible fouling. The model gave a fairly good prediction on TMP variation with a low RMSE of $5.4 \%$ during the final period.

\section{Model performance with the MBER-2 data}

The MBER-2 was a modified MBER-1 with AEM as a separator for enhancing nitrogen removal through nitrate migration driven by electricity generation and denitrification. Thus, nitrogen was a new parameter for the model to include. This MBER was fed with an anolyte at $1.34 \mathrm{~mL} \mathrm{~min}^{-1}$ in a hydraulic full-loop mode until day 60 . The developed model gave good prediction on current generation from a synthetic solution with slight overestimation and a low RMSE of $10.7 \%$ (Fig. 3a). The using of carbon brush and enhanced separator area resulted in an improved electrical performance (compared to the MBER-1). The substrate consumption in the anodic chamber was also simulated (Fig. 3b), and the simulated results suggest that the MBER-2 almost reached a steady state in 40 days with a low concentration of residual chemical oxygen demand (COD). It should be noted that the measurement was taken once a week, and future studies to improve the developed model will require more frequent measurement. Cake mass accumulation endured a dynamic process, in which a peak TMP value of $10 \mathrm{kPa}$ was obtained on day 30 and it dropped back to $5 \mathrm{kPa}$ on day 60 (Fig. 3c), due to the low suspended solids and organic content from the anolyte. The simulated concentration of total nitrogen concentration in membrane permeate exhibited a satisfactory agreement with the experimental measurement (Fig. 3d), and the mean error for the total nitrogen concentration was within $6.5 \%$ of their maximum values. Equation 26 indicates that the concentration gradient-driven diffusion from the cathodic to the anodic compartment and the ion migration-driven by ionic current and charge balance, which is described by the Faraday's law, are two major mechanisms for nitrogen removal. Compared to ion 

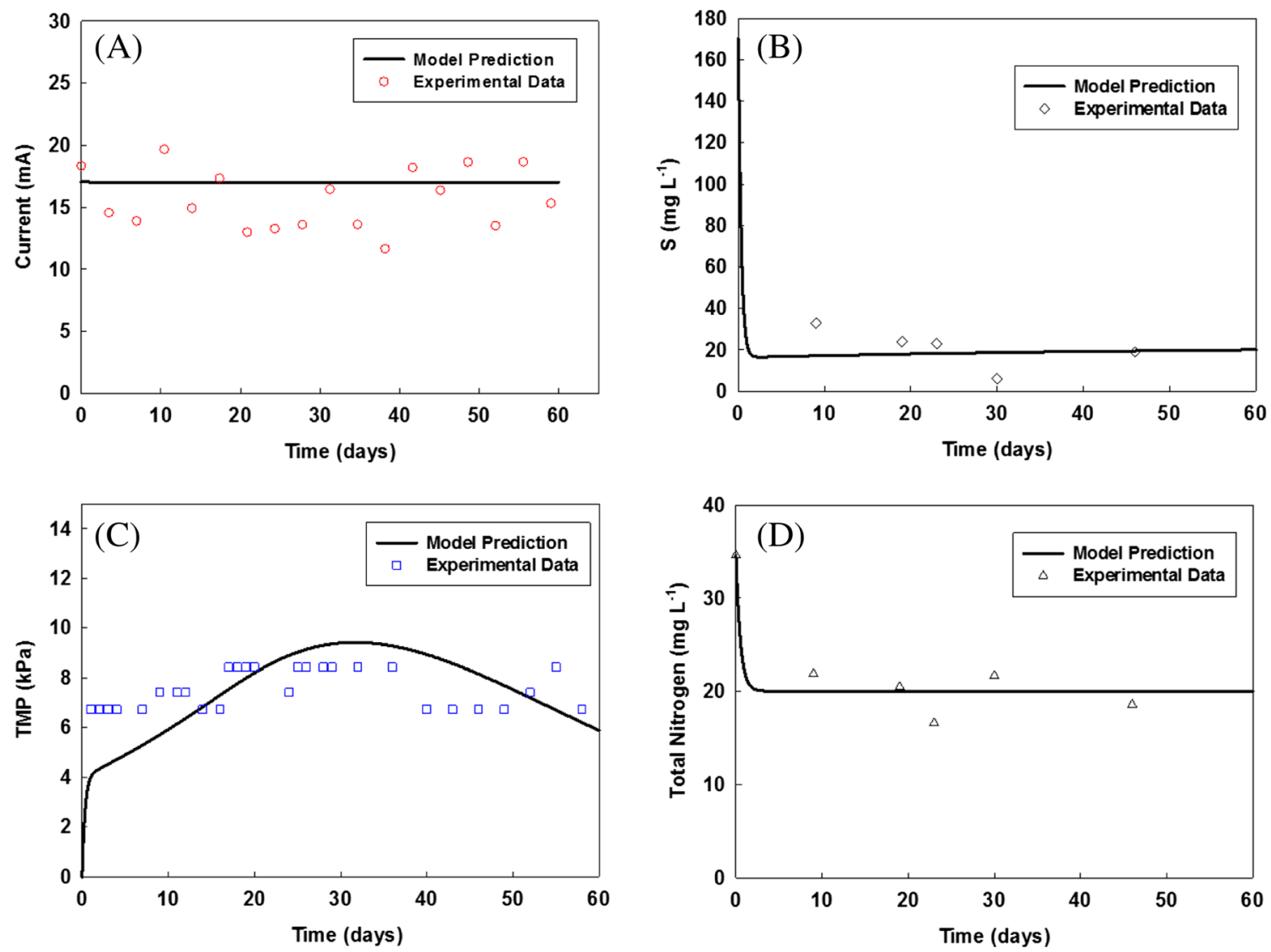

Fig. 3 Experimental data and model simulation of the MBER-2 fed with a synthetic solution: a current generation, $\mathbf{b}$ substrate concentration in the anode effluent, $\mathbf{c}$ TMP change, and $\mathbf{d}$ total nitrogen $(\mathrm{TN})$ concentration in the membrane permeate

migration effect, ion diffusion from concentration gradient played a minor role for nitrogen removal. A coefficient $\alpha$ (0.13) was applied to modify on ion migration, which indicates about $13 \%$ of generated electrons was used for driving negatively charged nitrate ions into the anodic compartment and other negatively charged ions such as chlorine and sulfate may use the rest of electrons.

The MBER-2 was also operated by feeding actual wastewater, a primary effluent from a local wastewater treatment plant, at $1.25 \mathrm{~mL} \mathrm{~min}^{-1}$, resulting in anodic HRT of $10 \mathrm{~h}$, and the data obtained from actual wastewater were also used for model validation. In general, the developed model can well predict TMP and total nitrogen (Fig. 4c, d), with low RMSE of 8.6 and $9.7 \%$, respectively. The current predication (Fig. 4a) has a high RMSE of $24.8 \%$, mainly because of the fluctuating current generation with actual wastewater. It should be noted that the conductivity of the primary effluent was below $1 \mathrm{mS} \mathrm{cm}{ }^{-1}$, much lower than $3.3 \mathrm{mS} \mathrm{cm}{ }^{-1}$ of the synthetic solution; therefore, the parameter $R_{\min }$ was re-designated as $300 \Omega$ for model fitting. The COD consumption in the anodic compartment was predicted with underestimation, with simulated COD concentration about $10 \mathrm{mg} \mathrm{L}^{-1}$ higher than the experimental measurement (Fig. 4b). The new $R_{\min }$ might be responsible for this discrepancy, but this warrants further investigation.

\section{Model performance with the MBER-3 data}

The MBER-3 was a fluidized-bed system with GAC as media. The fluidized GAC was affected by the anolyte recirculation; thus, recirculation strategy was examined. The developed model showed a satisfactory agreement of current prediction with the experimental measurement, and its RMSE was within $8.8 \%$ of their maximum value (Fig. $5 \mathrm{a}$ ). The slight overestimation of current between days 10 and 43 was related to the assumption that a homogeneous condition for substrate and biomass distribution is always valid, even though the absence of recirculation flow may retard substrate transfer to electrode surface. A significant mismatch with a high RMSE of $55.7 \%$ was observed on day 63 when the anodic HRT was changed to $5 \mathrm{~h}$. Such a discrepancy was likely related to several factors: the stacked GAC in the anodic chamber may have offset the effect of the enhanced flow rate of feeding solution, the electrochemically active biofilm on the electrode surface may require longer time for acclimating to new hydraulic condition, and/or the enhanced organics could 

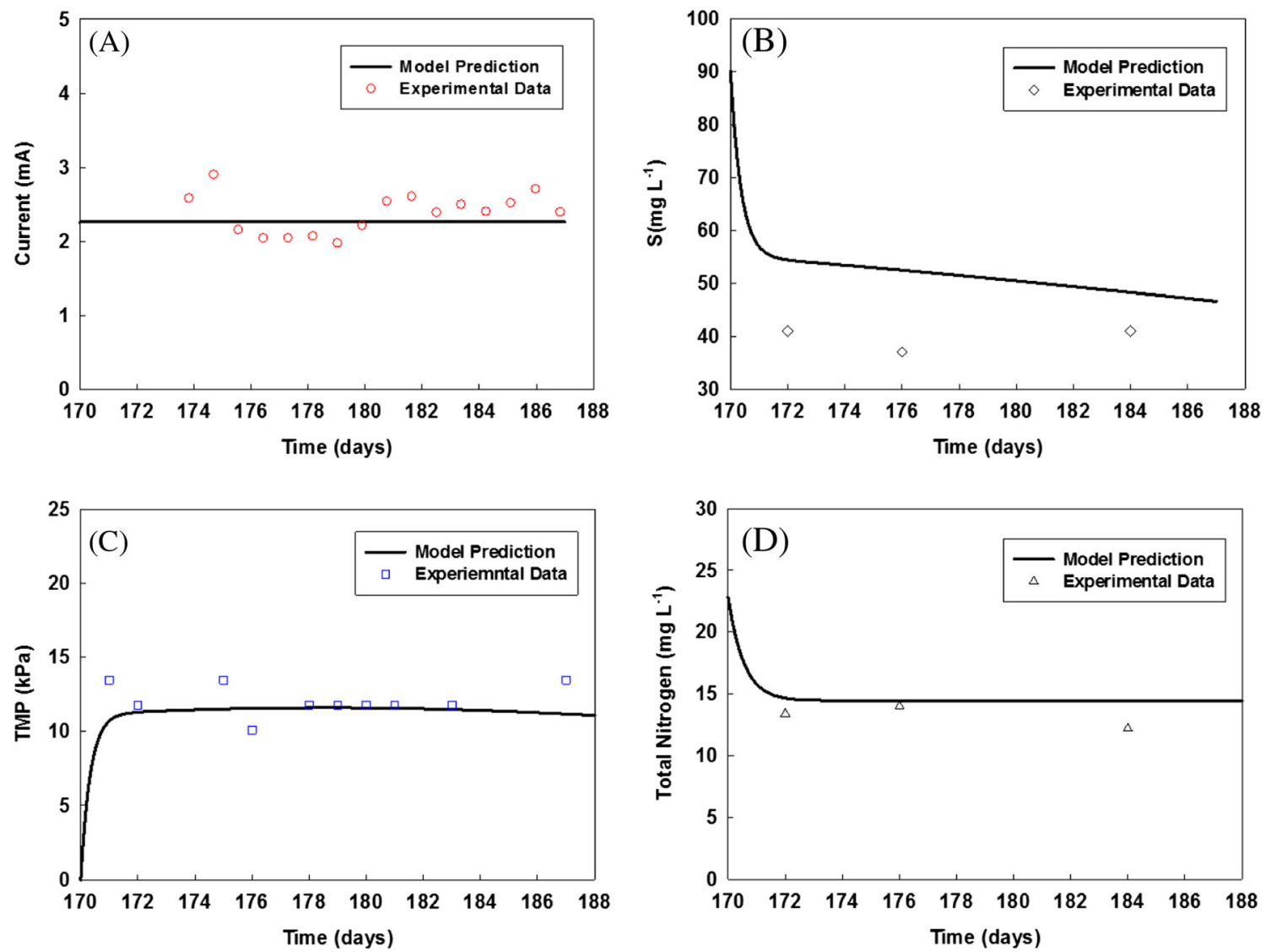

Fig. 4 Experimental data and model simulation of the MBER-2 fed with actual wastewater (primary effluent): a current generation, b substrate concentration in the anode effluent, $\mathbf{c}$ TMP change, and $\mathbf{d}$ total nitrogen (TN) concentration in the membrane permeate

be consumed by the non-electrochemically active microorganism on the GAC surface (which could be dominated in a mixed culture system).

The model gave a very good prediction for TMP change with a low RMSE of $9.0 \%$ (Fig. 5b). The change of filtration resistance $(R)$ correlates to water flux $(J)$ and hydraulic crossflow $\left(U_{L r}\right)$, which has been shown in Eqs. 23 and 25. The change of membrane resistance rate $(K)$ is proportional to water flux by a factorial of 0.38 and to hydraulic cross-flow inversely by a factorial of 1.1. The increase of TMP has been expressed in a linearized way after the recirculation flow was stopped, and the effect of $U_{L r}$ can be neglected due to the extremely low cross-flow on membrane surface. Therefore, since day 10, TMP has been increasing along with a slope, mainly determined by water flux. Water flux might have a minor effect after the recirculation flow was re-started, due to the quantitative relationship between $J$ and $U_{L r}$. Hence, filtration resistance is determined by hydraulic cross-flow in an inverse relationship, and a low TMP can be seen between day 43 to 63 . The model prediction of TMP was also validated after the MBER system was fed at $2.33 \mathrm{~mL} \mathrm{~min}^{-1}$ on day 63 , and based on the model results, hydraulic crossflow still could have played a dominant role for membrane fouling control.
The effects of multiple factors were studied focusing on water flux $(J)$ and hydraulic cross-flow on membrane surface $\left(U_{L r}\right)$, where these two parameters are changed simultaneously for evaluating filtration resistance change (Fig. 6). The simulation results show that a higher water flux can be compensated by increasing the recirculation rate. It is demonstrated that for a fixed water flux, the change of membrane resistance $K$ decreases upon the increase of hydraulic cross-flow at $0.0005 \mathrm{~m} \mathrm{~s}^{-1}$, corresponding to $630 \mathrm{~mL} \mathrm{~min}^{-1}$ recirculation flow in this MBER. The membrane has a minor fouling issue (or it requires a long time for noticeable fouling) when a recirculation flow rate is higher than $630 \mathrm{~mL} \mathrm{~min}^{-1}$. However, for a fixed recirculation flow rate lower than $630 \mathrm{~mL} \mathrm{~min}{ }^{-1}$, the change of filtration resistance increases upon the increase of water flux. Therefore, controlling recirculation flow rate at $630 \mathrm{~mL} \mathrm{~min}{ }^{-1}$ can be an optimum operation method to minimize membrane fouling issue, thereby extending membrane's lifetime and reducing energy consumption, in the absence of aeration and chemical cleaning.

\section{Perspectives}

This work represents the first attempt to model membrane bioelectrochemical systems, and the developed model can 

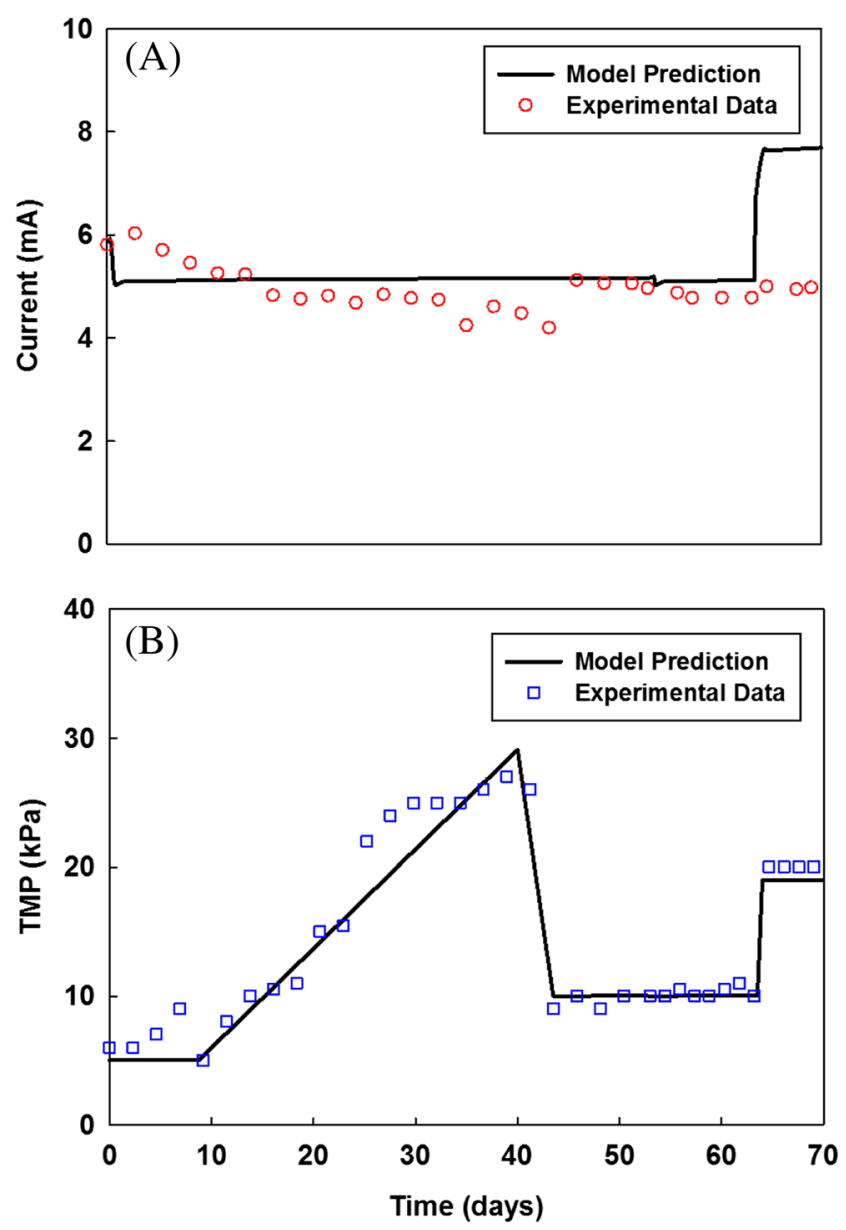

Fig. 5 Experimental data and simulation results of the MBER-3 a current generation and b TMP change. The anodic HRT was $8 \mathrm{~h}$ with $800 \mathrm{~mL} \mathrm{~min}^{-1}$ recirculation during days 0 and 53; recirculation stopped on day 10 and resumed on day 43 , with $600 \mathrm{~mL} \mathrm{~min}^{-1}$ on day 53. The anodic HRT decreased to $5 \mathrm{~h}$ with $800 \mathrm{~mL} \mathrm{~min}^{-1}$ recirculation on day 63

effectively predict the key parameters of an MBER such as current generation, substrate consumption, and TMP.

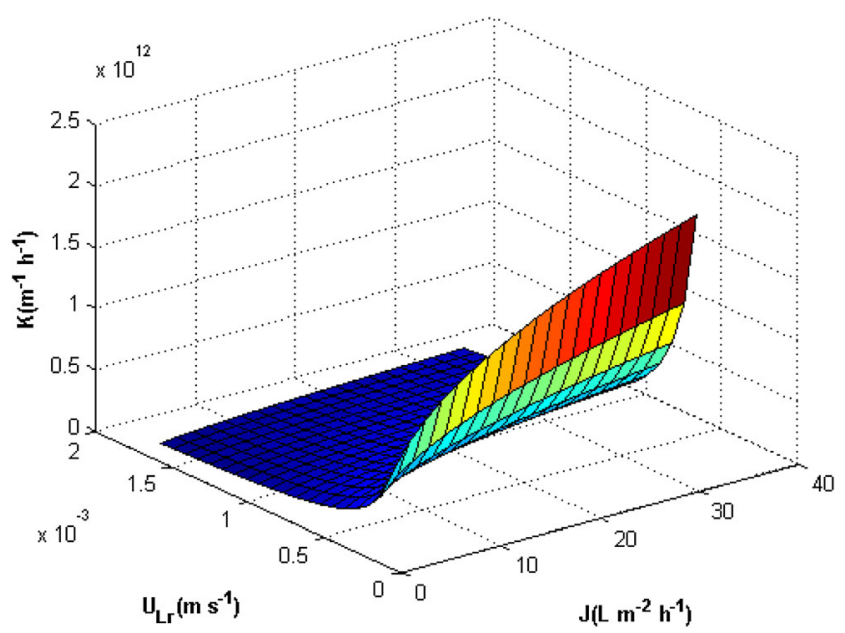

Fig. 6 Model simulation of the effects of multiple factors including membrane filtration resistance $(K)$, cross-flow velocity $\left(U_{L r}\right)$, and water flux $(J)$
However, limitations still exist in the current model. For example, the present model is based on the assumption that a homogeneous condition has been well established within an MBER; although this assumption simplifies simulation and calculation procedures, such an ideal condition cannot be easily obtained with real operation. In addition, the model assumes that the overpotential of both anode and cathode electrodes is kept constant in a low range, which may not always be the case because the residual organics from the anode chamber can act as a source of organics for the microbial simulation in the cathode, and as a result, the overpotential will vary. Furthermore, other factors such as nitrogen consumption due to the microbial synthesis have not been accounted for total nitrogen simulation. Future studies will optimize and advance this MBER model from several aspects: (1) complex substrates and substrate gradient and heterogeneous spatial distribution of microorganism will be considered, (2) dynamic variation of electrode overpotentials will be included, (3) other biological processes such as denitrification should be included for the organic consumption, and (4) the model will be used to guide the system scaling up for developing large-scale MBER system for treating actual wastewater.

\section{Conclusions}

A dynamic mathematical model has been developed and used to simulate/predict the key parameters of the MBER systems, such as current generation, substrate consumption, membrane fouling, and nitrogen removal. It was adjusted to successfully model three different types of MBER systems with distinct features such as nitrogen removal and fluidized GAC. The model gave a satisfactory agreement with experimental data, but some under/overestimation was observed. The results of this work encourages further optimization of this MBER model through including more dynamic factors, and ultimately, the model can guide the development of large-scale MBER systems for actual wastewater treatment.

Acknowledgments This research was financially supported by a grant from National Science Foundation (\#1358145). The authors would like to thank Ms. Qingyun Ping (Virginia Tech) for her help with model development.

\section{References}

Diez V, Ezquerra D, Cabezas J, García A, Ramos C (2014) A modified method for evaluation of critical flux, fouling rate and in situ determination of resistance and compressibility in MBR under different fouling conditions. J Membr Sci 453:1-11 
Ge Z, Ping Q, He Z (2013) Hollow-fiber membrane bioelectrochemical reactor for domestic wastewater treatment. J Chem Technol Biotechnol 88:1584-1590

Judd S (2008) The status of membrane bioreactor technology. Trends Biotechnol 26:109-116

Kato Marcus A, Torres CI, Rittmann BE (2007) Conduction-based modeling of the biofilm anode of a microbial fuel cell. Biotechnol Bioeng 98:1171-1182

Khan SJ, Visvanathan C, Jegatheesan V (2009) Prediction of membrane fouling in MBR systems using empirically estimated specific cake resistance. Bioresour Technol 100:6133-6136

Li J, He Z (2015) Optimizing the performance of a membrane bioelectrochemical reactor using an anion exchange membrane for wastewater treatment. Environ Sci Water Res Technol 1:355-362

Li J, Ge Z, He Z (2014a) Advancing membrane bioelectrochemical reactor (MBER) with hollow-fiber membranes installed in the cathode compartment. J Chem Technol Biotechnol 89:1330-1336

Li J, Ge Z, He Z (2014b) A fluidized bed membrane bioelectrochemical reactor for energy-efficient wastewater treatment. Bioresour Technol 167:310-315

Li WW, Yu HQ, He Z (2014c) Towards sustainable wastewater treatment by using microbial fuel cells-centered technologies. Energy Environ Sci 7:911-924

Li J, Zhu Y, Zhuang L, Otsuka Y, Nakamura M, Goodell B, Sonoki T, He Z (2015) A novel approach to recycle bacterial culture waste for fermentation reuse via a microbial fuel cell-membrane bioreactor system. Bioprocess Biosyst Eng. doi:10.1007/s00449-015-1420-9

Liu R, Huang X, Sun YF, Qian Y (2003) Hydrodynamic effect on sludge accumulation over membrane surfaces in a submerged membrane bioreactor. Process Biochem 39:157-163

Logan BE, Hamelers B, Rozendal R, Schröder U, Keller J, Freguia S, Aelterman P, Verstraete W, Rabaey K (2006) Microbial fuel cells: methodology and technology. Environ Sci Technol 40:5181-5192

$\mathrm{Ng}$ AN, Kim AS (2007) A mini-review of modeling studies on membrane bioreactor (MBR) treatment for municipal wastewaters. Desalination 212:261-281
Picioreanu C, Head IM, Katuri KP, van Loosdrecht MCM, Scott K (2007) A computational model for biofilm-based microbial fuel cells. Water Res 41:2921-2940

Pimentel GA, Vande Wouwer A, Harmand J, Rapaport A (2015) Design, analysis and validation of a simple dynamic model of a submerged membrane bioreactor. Water Res 70:97-108

Ping Q, Zhang C, Chen X, Zhang B, Huang Z, He Z (2014) Mathematical model of dynamic behavior of microbial desalination cells for simultaneous wastewater treatment and water desalination. Environ Sci Technol 48:13010-13019

Pinto R, Srinivasan B, Manuel M-F, Tartakovsky B (2010) A twopopulation bio-electrochemical model of a microbial fuel cell. Bioresour Technol 101:5256-5265

Rabaey K, Verstraete W (2005) Microbial fuel cells: novel biotechnology for energy generation. Trends Biotechnol 23:291-298

Ren LJ, Ahn YT, Logan BE (2014) A two-stage microbial fuel cell and anaerobic fluidized bed membrane bioreactor (MFC-AFMBR) system for effective domestic wastewater treatment. Environ Sci Technol 48:4199-4206

Wang YK, Sheng GP, Li WW, Huang YX, Yu YY, Zeng RJ, Yu HQ (2011) Development of a novel bioelectrochemical membrane reactor for wastewater treatment. Environ Sci Technol 45:9256-9261

Wang YP, Liu XW, Li WW, Li F, Wang YK, Sheng GP, Zeng RJ, Yu HQ (2012) A microbial fuel cell-membrane bioreactor integrated system for cost-effective wastewater treatment. Appl Energy 98:230-235

Yuan $\mathrm{H}$, He Z (2015) Integrating membrane filtration into bioelectrochemical systems as next generation energy-efficient wastewater treatment technologies for water reclamation: a review. Bioresour Technol. doi:10.1016/j.biortech.2015.05.058

Zhang F, Ge Z, Grimaud J, Hurst J, He Z (2013) Long-term performance of liter-scale microbial fuel cells treating primary effluent installed in a municipal wastewater treatment facility. Environ Sci Technol 47: 4941-4948

Zuthi M, Ngo H, Guo W, Nghiem L, Hai F, Xia S, Zhang Z, Li J (2015) Biomass viability: an experimental study and the development of an empirical mathematical model for submerged membrane bioreactor. Bioresour Technol 190:352-358 